\title{
PENERAPAN MODEL DECISION TREE ALGORITMA UNTUK MENGIDENTIFIKASI PENYAKIT PENCERNAAN DENGAN PENGOBATAN HERBAL
}

\author{
Nuraida Latif ${ }^{1}$, Ashari ${ }^{2}$ \\ Teknik Komputer ${ }^{1}$, Teknik Informatika ${ }^{2}$ \\ STMIK AKBA Makassar \\ Jl. Perintis Kemerdekaan Km 9 No. 75 Makassar Sulawesi Selatan Indonesia \\ nuraida@akba.ic.id, ashari@akba.ic.id
}

\begin{abstract}
Abstrak
Penelitian ini bertujuan untuk mengidentifikasi penyakit pencernaan dengan pengobatan herbal menggunakan model decision tree algoritma. Penyakit pencernaan merupakan salah satu penyakit yang banyak di derita oleh manusia, dan mengalami peningkatan tiap tahunnya. Pencernaan merupakan salah satu organ manusia yang sangat penting bagi tubuh manusia. Pentingnya kinerja organ pencernaan yang ada di dalam tubuh manusia membuat manusia harus menjaga kesehatan agar tubuh tetap bekerja dengan baik. Pengetahuan masyarakat yang sedikit akan gejala-gejala awal dari suatu penyakit merupakan faktor-faktor penyakit menjadi parah ketika penderita ditangani oleh tenaga paramedis. Data-data penelitian dilakukan dengan penelitian lapangan, studi pustaka, wawancara. Berdasarkan pengujian dan penggunaan sistem informasi, didapatkan hasil quisioner yang menyatakan baik dengan pengujian terhadap kemudahan penggunaan (daya guna) diperoleh hasil 90\%, fungsionalitas diperoleh hasil 90\%, antarmuka pengguna diperoleh hasil 95\%, efisiensi diperoleh hasil 95\%, integritas (keamanan) diperoleh hasil 90\%, kemampuan adaptasi sistem diperoleh hasil 92,5\%, keakuratan diperoleh hasil 90\% dan kemudahan instalasi software diperoleh hasil $90 \%$.
\end{abstract}

Kata Kunci : Penyakit, Pencernaan, Pengobatan herbal, Decision Tree algoritma.

The aims of the study to identify digestive diseases with herbal medicine using the algorithm decision tree model. Digestive disease is one of the many diseases suffered by humans, and has increased every year. Digestion is one of the human organs that is very important for the human body. The importance of the performance of digestive organs in the human body makes humans have to maintain health so that the body continues to work well. Knowledge of the community with a slight initial symptoms of an illness is a disease factor that becomes severe when the patient is treated by paramedics. The research data is done by field research, literature study, interview. Based on the testing and use of the information system, the results of the quisioner were found to be good by testing the ease of use (usability), the results obtained $90 \%$, the functionality obtained results $90 \%$, the user interface obtained $95 \%$ results, the efficiency obtained $95 \%$ results, integrity (security) the results obtained $90 \%$, the system adaptability is the result of $92.5 \%$, the accuracy of the results obtained $90 \%$ and the ease of software installation results obtained $90 \%$.

\section{Keywords : Digestive, Disease, Herbal Medicine, Decision Tree algorithm.}




\section{Pendahuluan}

Semakin berkembangnya ilmu pengetahuan dan teknologi dengan pesat akan menginspirasi manusia menciptakan suatu hal yang baru. Salah satu contohnya dalam penggunaan teknologi komputer. Komputer yang biasanya hanya digunakan untuk mengolah data dan melakukan perhitungan matematika, saat ini sudah dapat dimanfaatkan sebagai pemberi solusi terhadap masalah yang diinputkan, seperti halnya Decision Tree Algoritma. Decision Tree Algoritma merupakan bagian dari pengembangan teknologi informasi yang saat ini telah banyak membantu kebutuhan manusia. Saluran pencernaan merupakan gerbang utama masuknya zat gizi sebagai sumber pemenuhan kebutuhan tubuh baik untuk melakukan metabolisme hingga aktivitas sehari-hari. Lambung merupakan tempat yang paling utama makanan dicerna untuk diserap sebagai zat gizi, oleh sebab itu kesehatan lambung menjadi hal yang sangat penting dalam optimalisasi pencernaan dan penyerapan gizi (Anggita, 2012).

Gangguan lambung seperti gastritis merupakan salah satu penyakit yang paling banyak dijumpai di klinik penyakit dalam dan kehidupan sehari-hari (Hirlan, 2009). Penyakit dalam semakin berkembang setiap tahunnya, terutama gangguan pada sistem pencernaan manusia yang merupakan salah satu organ penting bagi tubuh manusia. Pentingnya kinerja organ pencernaan yang ada di dalam tubuh manusia membuat manusia harus menjaga kesehatan agar tubuh tetap bekerja dengan baik. Pengetahuan masyarakat yang sedikit akan gejala-gejala awal dari suatu penyakit merupakan faktor-faktor penyakit menjadi parah ketika penderita ditangani oleh tenaga paramedis. Namun, terbatasnya jumlah, waktu dan tenaga dari seorang dokter spesialis penyakit dalam, sehingga terjadi keterlambatan bagi penderita mendapatkan penanganan terhadap penyakit yang dideritanya, yang berakibat pada semakin parah atau mungkin bisa mengakibatkan kematian penderita. Masyarakat juga membutuhkan informasi penyakit yang dideritanya mulai dari gejala yang terjadi, penentuan jenis penyakit sampai dengan solusi untuk mengatasi penyakit masih bergantung kepada dokter spesialis penyakit pencernaan. Selain jumlah dokternya masih sedikit, biaya yang dibutuhkan berkonsultasi juga tidak sedikit. Berdasarkan latar belakang yang disebutkan diatas, maka penulis mengajukan judul penelitian yaitu "Penerapan Model Decision Tree Algoritma untuk mengidentifikasi Penyakit Pencernaan dengan Pengobatan Herbal".

\section{Kerangka teori}

\subsection{Decision Tree}

Decision Tree adalah salah satu metode klasifikasi yang popular dan banyak digunakan secara praktis. Metode ini berusaha menemukan model klasifikasi yang tahan terhadap derau. Salah satu metode Decision Tree yang sangat popular adalah Iterative Dychotomizer versi 3 (ID3). Dua varian lain yang popular adalah C4.5 dan ASSISTANT.

Metode ID3 berusaha membangun model klasifikasi yang berupa decision tree (pohon keputusan) secara top-down (dari atas ke bawah). Caranya adalah dengan mengevaluasi semua attribute menggunakan suatu ukuran statistic, biasa berupa information gain, untuk mengukur efektifitas suatu atribut dalam mengklasifikasi himpunan sampel data.

\subsection{Algoritma ID3}

Iterative Dichotomiser 3 (ID3) adalah algoritma decision tree learning (algoritma pembelajaran pohon keputusan) yang paling dasar. Algoritma ini melakukan pencarian secara menyeluruh (greedy) pada semua kemungkinan pohon keputusan. Salah satu algoritma induksi pohon keputusan yaitu ID3 (Iterative Dichotomiser 3). ID3 dikembangkan oleh J. Ross Quinlan. Algoritma ID3 dapat diimplementasikan menggunakan fungsi rekursif (fungsi yang memanggil dirinya sendiri). Algoritma ID3 berusaha membangun decision tree (pohon keputusan) secara top-down (dari atas ke bawah) (David, 2004).

\subsection{Penyakit Pencernaan}

Penyakit gangguan pencernaan merupakan suatu penyakit yang terjadi akibat terganggunya sistem penceranaan manusia.penyebab utama dari penyakit gangguan pencernaan ini biasanya terjadi karna pola makanan yang tidak teratur dan kurang sehat serta stress, infeksi bakteri, cacing dan juga bias karena adanya gangguan pada lambung.banyak sekali penyakit yang berhubungan dengan gangguan pencernaan . 
Jenis-jenis penyakit pada pencernaan dan gejalanya:

1. Lambung

2. Dispepsia

3. Penyakit Apendiks (radang usus)

4. Penyakit gangguan perkembangan dan erupsi gigi

5. Penyakit periapikal

6. Penyakit Gusi

7. Penyakit kista rongga mulut dan penyakit pada rahang

8. Penyakit seriawan

9. Penyakit Tukak lambung

10. Penyakit batu empedu

11. Penyakit crohn

12. Penyakit radang hati

13. Penyakit Pangkreatitis

14. Penyakit usus turun

15. Penyakit hati

\subsection{Pencernaan manusia}

1) Anatomi fisiologi Sistem pencernaan sistem pencernaan manusia

Menurut Lin (Inayah, 2004),sistem penceranaan manusia mempunyai fungsi, antara lain:

a) Menerima nutrient yaitu mulut dari mulut sampai dengan lambung .lambung merupakan alat penerima makanan yang paling besar(resevoar)

b) Nutrient ke dalam bentuk molekul-molekul yang ukuranya cukup kecil untuk dapat mencapai dan memasuki aliran darah sehingga memungkinkan molekuklmolekul tersebut masuk ke dalam aliran darah dan dikirm ke seluruh jaringan.

c) Membuang sisa makanan yang tidak dapat dicerna oleh tubuh malalui anus.

2) Mulut,tenggorokan dan kerongkongan

Mulut merupakan jalan masuk dari sistem pencernaan dan sistem pernafasan ,kerongkongan merupakan saluran berotot dan berdinding tipis yang di lapisi oleh selaput lende kerongkongan menghubungkan tenggorokan dengan lambung.

3) Lambung

Lambung merupakan organ otot berongga yang besar dan berbentuk seperti kacang kedelai.Fungsi lambung adalah sebagai gudang makanan,yang berkontraksi secara

Ritmik (berirama) untuk mencampur makanan dan enzim-enzimnya.

4) Usus halus

Usus halus merupakan tabung panjang yang hidup. Usus berukuran 2.5 meter ini terletak di daerah umbilicus dan dikelilingi oleh usus besar

5) Usus besar

Usus besar merupakan tempat fermentasi makanan(pembusukan makanan yang tidak tercerna) yang di bantu oleh udara lembab,bakteri atau kondisi derajat keasaman yang cukup besar. Usus besar menghasilkan lender dan berfungsi menyerap air dan elektronik dari tinja.ketika mencapai rectum bentuknya menjadi padat.

6) Rektum

Rektum adalah bagian ujung usus besar yang berhubungan langsung dengan usus. Umumnya keadaan rektum kosong, karean tinja disimpan ditempat yang lebih tinggi ,yakni di kolon desendends(kiri) .jika kolon ini penuh dan tinja masuk ke dalam rektum akan timbul keinginan buang air besar.

7) Anus

Anus merupakan lambung di ujung saluran pencernaan dan menjadi tempat limbah makanan keluar dari tubuh.sebagian anus terbentuk dari permukaan tubuh (kulit) dan sebagian lagi dari usus.Penyakit pada pencernaan manusia lebih dikenal dengan nama gangguan pencernaan. Gangguan pada pencernaan adalah terhalangnya fungsi pencernaan atau kegagalan perut dalam mencerna makanan. Kebiasaan cara makan yang kurang baik bisa menimbulkan berbagai gangguan pada pencernaan, seperti rasa panas dalam perut, diare, pusing, sulit buang air besar, mual, perut kembung.

\section{Metodologi}

Penelitian yang akan dilakukan di sini akan lebih jelas apabila langkah-langkah pelaksanaan penelitian dari awal sampai akhir digambarkan dalam suatu bagan alir seperti pada Gambar 1 . 


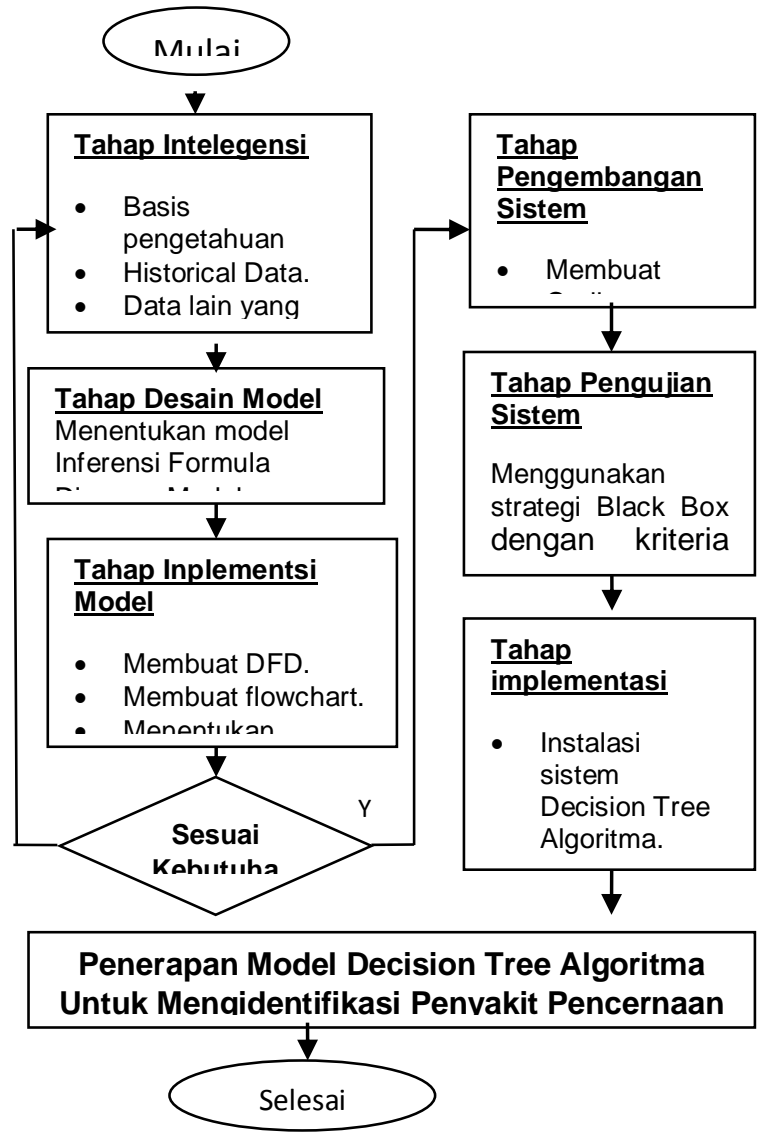

Gambar 1 Bagan alir penelitian

Sebelum melakukan kegiatan pengambilan data diadakan persiapan yang mendukung pelaksanaan studi seperti berikut.

1. Pengumpulan standar peta potensial wilayah sampel,

2. Penyiapan personil,

3. Penyiapan peralatan penjaringan data,

4. Penyiapan peralatan pengolahan data, dan

5. Diskusi dan rapat-rapat dengan unsur terkait.

Strategi pengujian sistem yang digunakan dalam penelitian ini yakni Black-box Testing. Kriteria atau karateristik pengujian sebagai berikut :

1. Karakteristik Luar, yaitu karakteristik yang dapat diamati secara langsung.

2. Karakteristik Dalam, karakteristik yang dipikirkan oleh pengembang, baik itu analis, desainer, atau pemrogram.

\subsection{Implementasi Sistem}

Implementasi system yang dilakukan dalam penelitian ini dengan aktivitas sebagai berikut :

1. Instalasi system Decision Tree Algoritma

2. Pembuiatan manual system/manual book

3. Menentukan refort/laporan system

\section{Hasil dan Pembahasan}

Halaman Utama merupakan tampilan antarmuka yang menampilkan aplikasi Decision Tree algoritma diagnosa penyakit pencernaan.

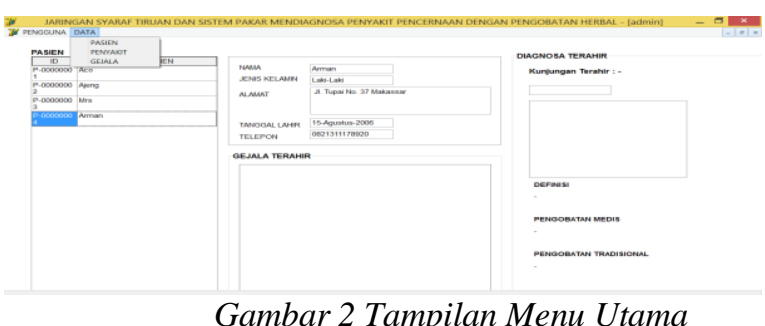

Form kelola pasien merupakan tampilan antarmuka tentang data pasien di klinik atau Puskesmas.

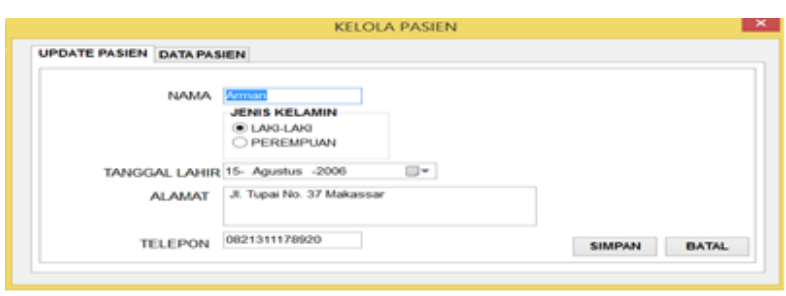

Gambar 3 Tampilan Form Kelola Pasien

Form kelola penyakit adalah form untuk menampilkan informasi data penyakit

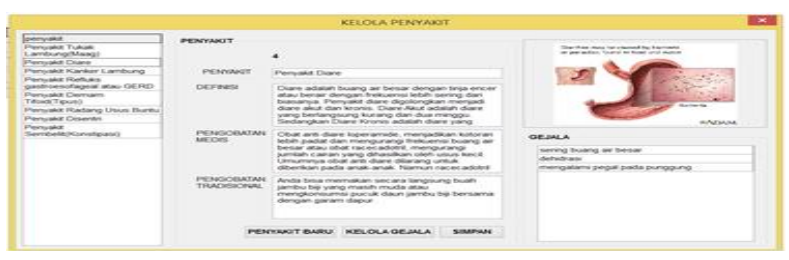

Gambar 4 Tampilan Form Kelola Penyakit 
Form kelola gejala merupakan form untuk menampilkan informasi daftar gejala

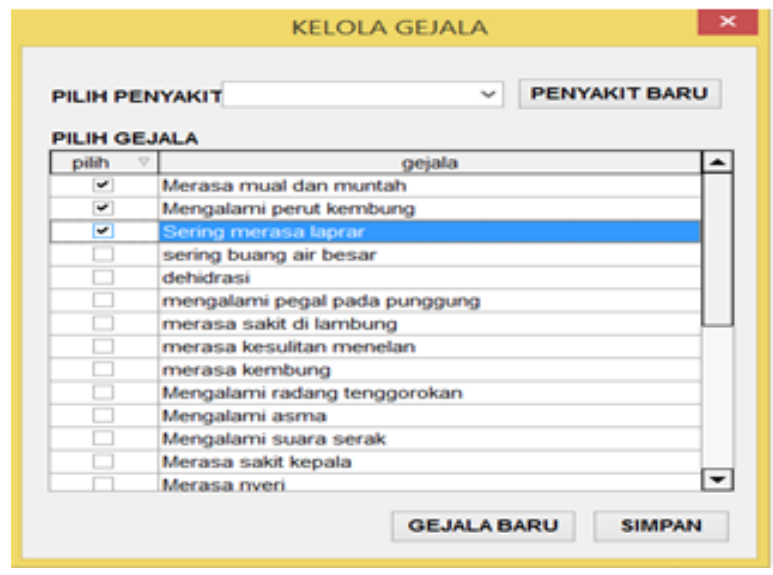

\section{Gambar 5 Tampilan Form Kelola Gejala}

Form diagnosa penyakit merupakan form yang digunakan untuk menampilkan hasil konsultasi pasien berdasarkan gejala penyakit dan memberikan solusi pengobatan secara medis dan herbal.

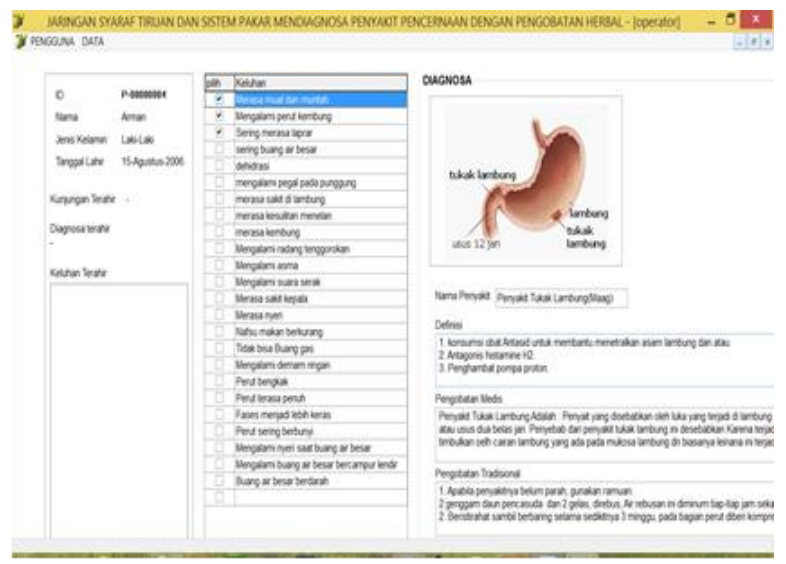

\section{Gambar 6 Tampilan Form Hasil \\ Diagnosa Penyakit}

Selanjutnya dilakukan pengujian model black box dengan melakukan text case dengan mempartisi domain input dengan cara memberikan cakupan pengujian yang mendalam. Pengujian dilakukan dengan black box.
Pengujian yang dilakukan melibatkan pihak pengguna sistem dan para pakar, meliputi : dokter, paramedis, petugas klinik, praktisi IT, dan mahasiswa sistem informasi.

Berdasarkan hasil pengujian dan penggunaan sistem informasi didapatkan hasil quisioner yang menyatakan baik dengan pengujian terhadap kemudahan penggunaan (daya guna) diperoleh hasil $90 \%$, fungsionalitas diperoleh hasil 90\%, antarmuka pengguna diperoleh hasil $95 \%$, efisiensi diperoleh hasil 95\%, integritas (keamanan) diperoleh hasil $90 \%$, kemampuan adaptasi sistem diperoleh hasil 92,5\%, keakuratan diperoleh hasil $90 \%$ dan kemudahan instalasi software diperoleh hasil $90 \%$.

\section{Kesimpulan}

$\begin{array}{rlr}\text { Berdasarkan hasil penelitian sementara } & \\ \text { terhadap model Decision Tree algoritma }\end{array}$ pendiagnosaan penyakit pencernaaan dan pengobatan cara herbal ini, dapat disimpulkan bahwa :Model decision Tree Algoritma, telah dilaksanakan penelitian untuk pendiagnosaan penyakit pencernaaan dengan pengobatan cara herbal dengan memberikan hasil pendiagnosaan dan hasilnya cukup baik berdasarkan gejala - gejala yang diberikan dengan cepat dan akurat, sehingga aplikasi ini mampu menjelaskan penyebab serta cara pengobatan dan pencegahan dari hasil diagnosa penyakit yang dilakukan sistem. Model Decision Tree Algoritma pendiagnosaan ini telah selesai sampai tahap implementasi dan diharapkan dapat mendiagnosa penyakit pencernaan dengan pengobatan cara herbal untuk mengatasi kekurangan tenaga ahli dalam memberikan pelayanan maksimal kepada masyarakat.

\section{Daftar Pustaka}

[1] Abdullah. (2008), Ilmu penyakit dalam (internal Medical diseases). Medan: sumatera utara.

[2] Almatseir. (2004). Prinsip Dasar Ilmu Gizi, Jakarta: Gramedi Pustaka Utama

[3] Aryanto, Herbal. 2013. Obat Infeksi Saluran Pencernaan Tradisional yang Aman. Tasikmalaya: ILLG 
[4] Al Fatta, Hanif . 2007. Analisis \& Perancangan Sistem Informasi. Yogyakarta: Penerbit Andi.

[5] Arham, Muhammad, 2005. Konsep Dasar Sistem Pakar, Yogyakarta : Penerbit Andi.

[6] David, M. (2004). Tutorial: The ID3 Decision Tree Algorithm. Monash: University facukty of information technology.

[7] Inayah (2004). Sistem Pakar untuk Diagnosa Penyakit pencernaan pada manusia word scientific: Co.pte.Lte.Singapura..

[8] Kadir Abdul, 2010, Mudah mempelajari database access. Yogyakarta: Penerbit Andi.

[9] Kristanto, Andri. 2008. Perancangan Sistem Informasi dan Aplikasinya. Yogyakarta ; Gava Media.

[10] Kusrini.2006, sistem pakar teori dan aplikasi. Yogyakarta: Penerbit Andi
[11] Kuwati, 2010. Sistem Pakar Pendeteksi Penyakit Saluran Pencernaan Pada Manusa.

[12] Roakch, L.d. (2008). Data Mining wirh decision tree theory and Aplication

[13] Suyanto, D. (2017). Data Mining untuk klasifikasi dari kalsterisasi data : Informatika Bandung.

[14] Sharif, M.2005.Parasit dan Penyakit. Malang:Penerbit UMM Press.

[15] Sutojo, T. dkk. 2011. Kecerdasan Buatan. Yogyakarta: Penerbit Andi.

[16] Yuswanto,Subari. 2008 Panduan lengkap pemograman visual basic 6.0. Yogyakarta: Penerbit Andi.

[17] Wahyono, Teguh. 2004. Sistem Informasi Konsep Dasar, Analisis Desain dan Implementasinya. Yogyakarta Penerbit : Graha ilmu 